\title{
An investigation into energy balance and macronutrient intakes of university students
}

\author{
J. Ellis ${ }^{1}$, R. Costa ${ }^{2}$ and F. Amirabdollahian ${ }^{1}$ \\ ${ }^{1}$ Department of Health Sciences, Liverpool Hope University, Liverpool, L16 $9 J \mathrm{~J}$ and ${ }^{2}$ Department of Health Professions, \\ Coventry University, Coventry, CVI 5FB, UK
}

Previous studies have demonstrated that university students often consume unhealthy snacks and convenience fast foods ${ }^{(1)}$. A swift decline in physical activity is also reported among them ${ }^{(2)}$, overall supporting the notion that university students are susceptible to unhealthy dietary practices and positive energy balance ${ }^{(3)}$. The purpose of this study was to investigate the state of energy balance of university students via comparing their current intake versus the estimate of the energy requirement for each participant.

The participants $(n=319)$ aged 18-30 from two UK universities were interviewed using a validated questionnaire. The anthropometric measures such as weight and height were also collected and used for calculations of energy requirement. The energy requirement was estimated based on calculations of basal metabolic rate (BMR) and physical activity level (PAL) in line with the most recent recommendations of Scientific Advisory Committee on Nutrition ${ }^{(4)}$. Energy intake was measured via a 24-hour diet recall validated by a 4-day weighted record in a subsample of the population $(n=54)$. Normal distribution was investigated using the Shapiro-Wilk test of normality and because the main variables were not normally distributed $(P<0.05)$, energy intake and requirement were compared using the nonparametric Wilcoxon Rank Test. Statistical analysis were conducted using SPSS 19 and statistical significance was set at 0.05 .

The median energy intake was significantly lower than the median energy expenditure $(8289.7 \mathrm{~kJ}$ Vs. $9941.2 \mathrm{~kJ}, P<0.05)$. This finding was consistent between both males and females. For males, the median contribution of macronutrient to energy intake was $16.6 \%, 51.2 \%$ and $31 \%$ for protein, carbohydrate and fat, respectively. For females' median contribution to energy intake was $15 \%, 54.6 \%$ and $29 \%$ for protein, carbohydrate and fat, respectively. The detail of energy intake and requirement as well contribution of macronutrient intake to energy intake for males and females are demonstrated in Table 1.

\begin{tabular}{|c|c|c|c|c|c|c|}
\hline \multirow[b]{2}{*}{ Energy and Macronutrients } & \multirow[b]{2}{*}{ Median } & \multicolumn{2}{|c|}{$\begin{array}{c}\text { Males } \\
\text { Quartiles }\end{array}$} & \multirow[b]{2}{*}{ Median } & \multicolumn{2}{|c|}{$\begin{array}{c}\text { Females } \\
\text { Quartiles }\end{array}$} \\
\hline & & $\mathbf{P} 25$ & P75 & & $\mathbf{P 2 5}$ & $\overline{P 75}$ \\
\hline Energy intake $(\mathrm{kJ})$ & 9732.0 & 7450.4 & 12271.7 & 7416.1 & 5968.5 & 8872.1 \\
\hline Estimated energy requirement $(\mathrm{kJ})$ & 11863.2 & 11018.2 & 12788.9 & 8891.6 & 8279.1 & 9517.3 \\
\hline Carbohydrate (g) & 274.6 & 206.3 & 361.4 & 228.0 & 178.3 & 286.5 \\
\hline Complex $(g)$ & 161.7 & 120.3 & 205.0 & 126.6 & 99.9 & 155.1 \\
\hline Sugar $(g)$ & 97.2 & 67.1 & 160.3 & 96.1 & 66.1 & 137.8 \\
\hline Fibre $(g)$ & 13.7 & 9.5 & 20.6 & 12.9 & 9.9 & 19.0 \\
\hline Fat $(\mathrm{g})$ & 82.0 & 56.6 & 109.0 & 60.4 & 44.7 & 81.3 \\
\hline Saturated $(g)$ & 30.0 & 19.6 & 42.4 & 22.5 & 14.2 & 35.4 \\
\hline Monounsaturated fatty acids $(M U F A)(g)$ & 27.3 & 17.2 & 38.2 & 18 & 12.7 & 25.9 \\
\hline Polyunsaturated fatty acids (PUFA) $(g)$ & 19.0 & 13.0 & 27.2 & 14.5 & 8.8 & 19.8 \\
\hline Trans fatty acids $(\mathrm{g})$ & 1.5 & 0.8 & 2.9 & 1.3 & 0.7 & 2.3 \\
\hline Protein $(\mathrm{g})$ & 91.1 & 71.7 & 123.7 & 66.1 & 51.0 & 86.3 \\
\hline
\end{tabular}

Energy intake was significantly lower than energy expenditure in university students in contrast to previous studies demonstrating that university students are potentially susceptible to positive energy balance. University students may benefit from reducing their sugar and saturated fat intake and increasing their complex carbohydrate and unsaturated fat intake.

1. Wengreen HJ \& Moncur C (2009) Nutr J 8, 1-7.

2. Grubbs L \& Carter J (2002) Fam Community Health 25, 76-84.

3. Hoffman DJ, Policastro P, Quick V \& Lee SK (2006) J Am Coll Health 55, 41-5.

4. Scientific Advisory Committee on Nutrition, Dietary Recommendations for Energy: 2011 (Prepublication copy). Available from: http://www.sacn.gov. uk/pdfs/sacn_energy_report_author_date_10th_oct_fin.pdf 